\title{
Irish surgeons college refuses to speak out against atrocities in Bahrain
}

This News story by Sophie Arie mistakenly stated that the Irish Medical Organisation (IMO) had refused to comment on the situation in Bahrain (BMJ 2011;342, doi:10.1136/bmj.d3259).

We should have said that the IMO was unable to answer the

$B M J$ 's questions in time for publication of this article. However, the article correctly said that the IMO had not commented publicly on the situation in Bahrain.

Cite this as: $B M J$ 2011;342:d3444 